\title{
Overexpression of Human SNX27 Enhances Learning and Memory Through Modulating Synaptic Plasticity in Mice
}

Yuanhui Huo ${ }^{1 t}$, Yue Gao ${ }^{1 t}$, Qiuyang Zheng ${ }^{1}$, Dongdong Zhao', Tiantian Guo', Shuo Zhang ${ }^{1}$, Yuzhe Zeng ${ }^{1}$, Yiyun Cheng ${ }^{1}$, Huaping Gu${ }^{1}$, Lishan Zhang ${ }^{1}$, Bin Zhu', Hong Luo', Xian Zhang', Ying Zhou ${ }^{2}$, Yun-wu Zhang ${ }^{1}$, Hao Sun ${ }^{1}$, Huaxi $X^{1}{ }^{1}$ and Xin Wang ${ }^{1 *}$

'State Key Laboratory of Cellular Stress Biology, Fujian Provincial Key Laboratory of Neurodegenerative Disease and Aging Research, Institute of Neuroscience, School of Medicine, Xiamen University, Xiamen, China, ${ }^{2}$ National Institute for Data Science in Health and Medicine, School of Medicine, Xiamen University, Xiamen, China

\section{OPEN ACCESS}

Edited by:

Da Jia,

Sichuan University, China

Reviewed by:

Zhifang Dong,

Chongqing Medical University, China Keiichi Kadoyama,

Himeji Dokkyo University, Japan

${ }^{*}$ Correspondence:

Xin Wang

wangx@xmu.edu.cn

†These authors have contributed equally to this work

Specialty section:

This article was submitted to Membrane Traffic,

a section of the journal

Frontiers in Cell and Developmental

Biology

Received: 16 August 2020 Accepted: 11 November 2020

Published: 27 November 2020

Citation:

Huo Y, Gao Y, Zheng Q, Zhao D, Guo $T$, Zhang $S$, Zeng $Y$, Cheng $Y$,

Gu H, Zhang L, Zhu B, Luo H, Zhang $X$, Zhou $Y$, Zhang $Y$, Sun $H$, $X u H$ and Wang $X(2020)$ Overexpression of Human SNX27 Enhances Learning and Memory

Through Modulating Synaptic Plasticity in Mice.

Front. Cell Dev. Biol. 8:595357. doi: 10.3389/fcell.2020.595357
Abnormal synaptic transmission leads to learning and memory disorders and is the main feature of neurological diseases. Sorting nexin 27 (SNX27) is an endosomal adaptor protein associated with a variety of nervous system diseases, and it is mainly responsible for the trafficking of postsynaptic membrane receptors. However, the roles of SNX27 in regulating synaptic and cognitive function are not fully understood. Here, we first generated a neuron-specific human-SNX27 transgenic mouse model (hSNX27 Tg) that exhibited enhanced excitatory synaptic transmission and long-term potentiation (LTP). In addition, we found that the hSNX27 Tg mice displayed enhanced learning and memory, lower-level anxiety-like behavior, and increased social interaction. Furthermore, we found that SNX27 overexpression upregulated the expression of glutamate receptors in the cortex and hippocampus of hSNX27 Tg mice. Together, these results indicate that SNX27 overexpression promotes synaptic function and cognition through modulating glutamate receptors.

Keywords: SNX27, trafficking, synaptic plasticity, learning and memory, glutamate receptors

\section{INTRODUCTION}

Synaptic function, especially the function of excitatory synapses, is closely associated with learning and memory (Kasai et al., 2010). Glutamate acts as the main neurotransmitter of excitatory neurons in mammalian brains and plays a key role in cognitive function (Niciu et al., 2012). Ionotropic $\alpha$-Amino-3-hydroxy-5-methyl4-isoxazolepropionic acid (AMPA) and $N$-methyl-D-aspartate (NMDA) glutamate receptors are two major types of postsynaptic receptors in glutamatergic synapses, which transmit presynaptic signals to postsynaptic neurons (Sheng and Kim, 2011). Activation

\footnotetext{
Abbreviations: AD, Alzheimer's disease; AMPA, $\alpha$-Amino-3-hydroxy-5-methyl-4-isoxazolepropionic acid; APP, amyloid precursor protein; Camk2a, Calcium/Calmodulin Dependent Protein Kinase II Alpha; DS, Down's syndrome; EEG, electroencephalogram; $\mathrm{GABA}_{A} \mathrm{R} \beta 3, \gamma$-aminobutyric acid type A receptor $\beta 3$ subunit; GAD-65, glutamic acid decarboxylase 65-kilodalton isoform; KA, Kainic acid; LTP, long-term potentiation; mEPSC, miniature excitatory postsynaptic current; mIPSC, miniature inhibitory postsynaptic current; NMDA, $N$-methyl-D-aspartate; PFA, Paraformaldehyde; PVDF, polyvinylidene difluoride; PX domain, the Phox homology domain; RA domain, the Ras-association domain; SNX27, Sorting nexin 27; Tg, Transgenic; WT, Wild-type.
} 
of NMDA receptors leads to long-term potentiation (LTP), which is regarded as a way of encoding "memories" in mammalian brains (Malenka, 2003; Kessels and Malinow, 2009). Mutations or abnormal expression of GluN1 (Chen et al., 2017), GluN2B (Hu et al., 2016) and GluA1 (Geisheker et al., 2017) are associated with intellectual disability.

As a member of the sorting nexin family proteins, Sorting nexin 27 (SNX27) contains a conserved phosphoinositidebinding domain (PX domain) which anchors SNX27 to the endosome membrane (Worby and Dixon, 2002; Seet and Hong, 2006; Cullen, 2008). In addition to PX domain, SNX27 contains a PDZ domain that binds transmembrane cargoes with PDZ binding motifs, and a FERM-like domain. Multiple transmembrane cargo proteins, including ion channels and receptors, are transported to plasma membrane by the SNX27-retromer complex (Gallon et al., 2014; Schulz and Hausmann, 2016).

Given that synaptic dysfunction and endo-lysosomal dysregulation represent the pathological features in neurodegenerative diseases (Acquarone et al., 2019; Chakroborty et al., 2019; Van Acker et al., 2019), such as Alzheimer's disease (AD) and Down's syndrome (DS), the role of SNX27 in these diseases has attracted extensive attention. In our previous study, we found premature lethality in $\operatorname{Sn} \times 27^{-/-}$mice. Moreover, we found that $\operatorname{Sn} \times 27^{+/-}$mice featured synaptic dysfunction and cognitive impairment, as well as the reduction in postsynaptic AMPA and NMDA receptors compared with that in $\operatorname{Sn} \times 27^{+/+}$ mice (Wang et al., 2013). In addition, SNX27 has been found to regulate amyloid precursor protein (APP) processing and $\mathrm{A} \beta$ generation through interacting with presenilin 1 (Wang et al., 2014). Furthermore, a deleterious homozygous mutation in SNX27 was identified in a consanguineous family with myoclonic epilepsy and neurodegeneration (Damseh et al., 2015). SNX27 deficiency lead to development and aging-related disorders; however, the physiological and pathological roles of SNX27 overexpression remain largely unclear.

Here, we generated a SNX27 transgenic mouse model that overexpresses human SNX27 specifically in excitatory neurons under the control of a Calcium/Calmodulin Dependent Protein Kinase II Alpha (Camk2a) promoter. The human-SNX27 transgenic (hSNX27 Tg) mice exhibited enhanced learning and memory, reduced anxiety-like behaviors, and increased social interaction, without seizure-like behavior. Furthermore, SNX27 overexpression enhanced excitatory synaptic transmission and plasticity through upregulating synaptic glutamate receptors and promoting synaptogenesis. These results indicate that SNX27 overexpression promotes synaptic transmission and cognitive function through regulating glutamate receptors in central nervous system.

\section{MATERIALS AND METHODS}

\section{Animals}

Human-SNX27 Tg mice overexpressing human SNX27 fused with HA under the control of the mouse Camk2a promoter were used in this study and were maintained on a C57BL/6 background. A piggyBac transposon gene expression vector and helper plasmid were injected into $\mathrm{C} 57 \mathrm{BL} / 6$ embryos to insert a segment containing the 1,296 bp mouse Camk2a promoter and the 1,614 bp human SNX27 sequence with HA tag and thereby generate hSNX27 Tg mice. The offspring mice were genotyped by PCR primers: F1: 5'-GATGAGATGCAGCGATGGG ACAC-3', R1: 5'-AGCCAGAAGTCAGATGCTCAAGG-3', F2: 5'-CAACCACT TACAAGAGACCCGTA-3', R2: 5'-GAGCCC TTAGAAATAACGTTCACC-3'.

Analysis was performed using 1\% agarose gel. A 632 bp product was verified for the wild-type (WT) allele, and a $368 \mathrm{bp}$ product was amplified for the transgenic allele.

Age-matched WT littermate mice were used as controls. All animal experiments were conducted in strict accordance with the guidelines of the Institutional Animal Care and Use Committee of Xiamen University.

\section{Quantitative Real-Time PCR}

Total RNA was extracted from brain tissues using TRIzol reagent (Thermo Fisher Scientific, Waltham, MA, United States) according to the manufacturer's instructions. cDNA was reverse transcribed using the ReverTra Ace qPCR RT Kit (TOYOBO, Osaka, Japan). Quantitative real-time PCR (qRTPCR) was accomplished using 7500 Fast V2.0.6 (Invitrogen, Shanghai, China) with the SYBR ${ }^{\circledR}$ Prime Script miRNA RT-PCR Kit (Takara). Actb was used as an internal control for quantitative analysis using the $2^{-\Delta \Delta C t}$ method. The gene primers used for real-time PCR were as follows: Mouse Snx27: 5'-GTGAACGGCGTGAATGTTGAG- $3^{\prime}$ and 5'-ACTGGGATCTAGGTTATC AGCC-3'; Mouse Grin1: 5'-A GCCCAACGCCATACAGATG-3' and $5^{\prime}$-ACGCGCATCATCT CAAACCA-3'; Mouse Grin2a: 5'-TGTGAACGTGGTGGC GTTAT- $3^{\prime}$ and $5^{\prime}$-TGGAAGAACGTGGATGTCGG-3'; Mouse Grin $2 b$ : 5'-ACGTCTCAAACC CTCGACAC-3' and $5^{\prime}$-GCG GCTCACAATGCAGAATC-3'; ${ }^{\prime}$ Mouse Grial: 5'-CGG TTTTCT AGGTGCGGTTG-3' and 5' -CCAAAGATGGCGTACACTCCT3'; Mouse Gria2: 5'-GGGGACTGATTTTTGGTGTCTC-3' and 5'-GCCTCTTGAAAACTGGG AGC-3'; and Actb: $5^{\prime}-$ AGCCATGTACGTAGCCATCCA- $3^{\prime}$ and $5^{\prime}$-TCTCCGGAGT CCATCACAATG-3'.

\section{Western Blot Analysis}

Brain tissues were lysed in RIPA buffer $(150 \mathrm{mM} \mathrm{NaCl}$, $25 \mathrm{mM}$ Tris- $\mathrm{HCl}, \mathrm{pH} 7.5,1 \%$ Nonidet P-40, $0.1 \%$ sodium dodecyl sulfate) supplemented with protease inhibitor cocktail (Roche, Mannheim, Germany). Protein lysates were denatured with SDS protein loading buffer, subjected to polyacrylamide gel electrophoresis (SDS-PAGE), and then transferred to polyvinylidene difluoride (PVDF) membranes (Millipore, Billerica, MA, United States). The membranes containing the extracted proteins were blocked with 5\% skim milk and then incubated with primary antibodies and horseradish peroxidase (HRP)-conjugated secondary antibodies (31430 or 31460 , Thermo Fisher Scientific, Waltham, MA, United States). Finally, protein band intensity was quantified using ImageJ software (National Institutes of Health, Bethesda, MD, United States) (Zheng et al., 2017). 
The following primary antibodies (all diluted 1:1,000) were used: rabbit anti-SNX27 (derived as described previously) (Cai et al., 2011), mouse anti-HA (901503, BioLegend, San Diego, CA, United States), rabbit anti- $\beta$-actin (Cell Signaling Technology, Danvers, MA, United States), rabbit anti-GluN2A (MAB5216, Millipore), mouse anti-GluN2B (610416, Millipore), rabbit anti-GluA1 (04-855, Millipore), mouse anti-GluA2 (AB1768, Millipore), mouse anti-GluN1 (MAB397, BD Biosciences, San Jose, CA, United States), mouse anti-synaptophysin (SAB4200544, Sigma, Burlington, MA, United States), mouse anti- $\gamma$-aminobutyric acid type A receptor $\beta 3$ subunit $\left(\mathrm{GABA}_{A} \mathrm{R} \beta 3\right.$ ) (sc-376252, Santa Cruz Biotechnology, Dallas, TX, United States), mouse anti-glutamic acid decarboxylase 65-kilodalton isoform (GAD-65) (sc377145, Santa Cruz Biotechnology) and mouse anti-PSD95 (MAB1598, Millipore).

\section{Immunohistochemistry}

Mouse brains were perfused with $4 \%$ paraformaldehyde (PFA) followed by dehydration with $30 \%$ sucrose. Then, $30-\mu \mathrm{m}$ sections were obtained using a freezing microtome (CM1950, Leica Buffalo Grove, United States) and rinsed with PBS. After hightemperature retrieval in sodium citrate buffer (MVS-0100, MX Biotechnologies) for $15 \mathrm{~min}$, the sections were incubated with primary antibodies overnight at $4^{\circ} \mathrm{C}$ and Alexa Fluor-conjugated secondary antibodies (Invitrogen, Carlsbad, CA, United States) for $2 \mathrm{~h}$ and then sealed with glycerin. Images were captured by confocal fluorescence microscope (Olympus, Japan). The antibodies used were as follows: rabbit anti-SNX27 (derived as described previously) (Cai et al., 2011); mouse anti-NeuN (MAB377, Millipore) and goat anti-mouse Alexa Fluor 405 (A31553)/488 (A-21141)/594 (A-21145) IgG ( H + L) and goat antirabbit Alexa Fluor 405 (A-31556)/488 (A32731)/594 (A32740) $\operatorname{IgG}(\mathrm{H}+\mathrm{L})$, both from Thermo Fisher Scientific.

\section{NissI Staining}

Mouse brain sections were stained using the Nissl Staining Kit (Beyotime, Shanghai, China) according to the manufacturer's protocol. Images were collected by optical microscopy and analyzed by ImageJ software.

\section{Golgi Staining and Analysis}

Brain slices were stained using the FD Rapid Golgi Stain Kit (FD NeuroTechnologies, Columbia, MD, United States) according to the manufacturer's instructions. Images were obtained using confocal microscope with Z-stack-compression and imported into ImageJ for calculating spine density.

\section{EEG Recording}

Human-SNX27 Tg and WT littermates were subjected to electroencephalogram (EEG) recording as previously described (Buckmaster and Lew, 2011; Zheng et al., 2016). C57BL/6 mice injected with Kainic acid (KA) (15 mg/kg, i.p.) were used as positive controls. In brief, mice were anesthetized with isoflurane $(0.5 \%)$ and kept warm throughout the experiment. A $0.1 \mathrm{~mm}$ diameter insulated microelectrode (Plastics One Inc.,
Roanoke, VA, United States) was implanted into the frontal and temporal area of each hemisphere (mediolateral, $\pm 1.8 \mathrm{~mm}$, anteroposterior, $-1.5 \mathrm{~mm}$ from the bregma). Another insulated stainless-steel wire (50 $\mu \mathrm{m}$ diameter, California Fine Wire) was inserted $1.7 \mathrm{~mm}$ under the mouse scalp. In addition, a reference electrode was planted in the cerebellum. Data were acquired and analyzed by Nicolet software (version 1.0).

\section{Electrophysiology}

Electrophysiology was performed as previously described (Zeng et al., 2019). The $400-\mu \mathrm{m}$ mouse brain slices were prepared using a Leica VT1200S vibrating microtome in ice-cold dissection solution $\left(64 \mathrm{mM} \mathrm{NaCl}, 2.5 \mathrm{mM} \mathrm{KCl}, 1.25 \mathrm{mM} \mathrm{NaH} \mathrm{PO}_{4}\right.$, $10 \mathrm{mM} \mathrm{MgSO}, 0.5 \mathrm{mM} \mathrm{CaCl}, 26 \mathrm{mM} \mathrm{NaHCO}, 10 \mathrm{mM}$ D-glucose, $120 \mathrm{mM}$ sucrose, $\mathrm{pH} 7.4,290-320 \mathrm{mOsm})$. Slices were left undisturbed for $1 \mathrm{~h}$ at $32^{\circ} \mathrm{C}$ and then equilibrated at room temperature for $1 \mathrm{~h}$ in artificial cerebrospinal fluid (aCSF) containing $126 \mathrm{mM} \mathrm{NaCl}, 3.5 \mathrm{mM} \mathrm{KCl}, 1.25 \mathrm{mM} \mathrm{NaH}_{2} \mathrm{PO}_{4}$, $1.3 \mathrm{mM} \mathrm{MgSO}_{4}, 2.5 \mathrm{mM} \mathrm{CaCl}_{2}, 11 \mathrm{mM} \mathrm{NaHCO}_{3}$, and $10 \mathrm{mM}$ glucose, $\mathrm{pH} 7.4,290-300 \mathrm{mOsm}$. Slices were transferred to the recording chamber and perfused with aCSF $(2 \mathrm{ml} / \mathrm{min})$. All recordings were performed at room temperature. All solutions were saturated with $95 \% \mathrm{O}_{2} / 5 \% \mathrm{CO}_{2}(\mathrm{v} / \mathrm{v})$.

For LTP recoding, field excitatory postsynaptic potentials (fEPSPs) were evoked by stimulating the Schaffer collateral/commissural pathway (for CA1) with a bipolar tungsten electrical stimulating electrode. Based on the stimulusresponse curve, a stimulation intensity that evoked a fEPSP response with $30 \%$ of the maximum response was selected and was recorded for $20 \mathrm{~min}$ (baseline). LTP was induced by high-frequency stimulation (two trains of $100 \mathrm{~Hz}$ with $1 \mathrm{~s}$ duration and $30 \mathrm{~s}$ interval). The field potential response after tetanic stimulation was recorded for $60 \mathrm{~min}$. LTP magnitude was quantified as the percentage change in the average fEPSP slope over $60 \mathrm{~min}$ after induction.

For whole-cell patch-clamp recording, all experiments were conducted on CA1 pyramidal neurons. Miniature excitatory postsynaptic current (mEPSC) and miniature inhibitory postsynaptic current (mIPSC) were recorded at a holding potential of -70 and $0 \mathrm{mV}$, respectively. Glass pipettes were filled with solution containing $140 \mathrm{mM} \mathrm{CsCH} \mathrm{SO}_{3}, 2 \mathrm{mM}$ $\mathrm{MgCl}_{2} \cdot 6 \mathrm{H}_{2} \mathrm{O}, 5 \mathrm{mM}$ TEA-CL, $10 \mathrm{mM}$ HEPES, $1 \mathrm{mM}$ EGTA, $2.5 \mathrm{mM} \mathrm{Mg-ATP}$, and $0.3 \mathrm{mM}$ Na-GTP, pH 7.3, $280 \mathrm{mOsm}$. Tetrodotoxin at $1 \mu \mathrm{M}$ was included in the perfusion solution for mEPSC and mIPSC recording. For evoked excitatory postsynaptic current (eEPSC) recording, we obtained inputoutput relationships at stimulation intensities from 40 to $320 \mu \mathrm{A}$. For the paired-pulse experiment, two pulses were measured with various inter-pulse intervals (20,50, 100, 200, and $500 \mathrm{~ms}$ ). The paired-pulse ratio was calculated by dividing the eEPSC response to the second pulse by the response to the first pulse. The resistance of the pipettes was 5-8 M $\Omega$. Data were filtered at $2 \mathrm{kHz}$ and sampled at $10 \mathrm{kHz}$.

\section{Behavioral Experiments}

All experiments were designed to avoid times of rest for the mice. Mice were allowed to adapt to the environment $1 \mathrm{~h}$ before testing 
and subjected to appropriate temperature and light throughout the process. All instruments were cleaned using $75 \%$ ethanol.

\section{Open Field Test}

An open field test (OFT) was used to assess athletic ability and anxiety-like responses during the exploratory behavior of mice. Mice were individually placed in the center of an open field $(40 \times 40 \times 40 \mathrm{~cm})$ and allowed to explore freely for $10 \mathrm{~min}$. Total distance, time spent in the center and entry times were recorded and analyzed using the Smart 3.0 video tracking system (Panlab, Harvard Apparatus, Holliston, MA, United States).

\section{Elevated Plus Maze}

An elevated plus maze (EPM) apparatus was used, which included two open arms and closed arms in staggered form. Mice were tested individually, with each mouse placed in the center square facing one of the open arms and away from the researcher. Total distance, duration of time and number of entries into each of the four arms over $8 \mathrm{~min}$ of exploration were measured.

\section{Light/Dark Transition Test}

This test was conducted to assess anxiety-like behavior in the mice. The testing box $(41 \times 41 \times 30 \mathrm{~cm})$ consisted of a light chamber and a dark chamber of equal size separated by a partition, through which the test mouse can pass freely. The test mouse was placed in the dark side and then tested for $8 \mathrm{~min}$. The total number of transitions and the total time spent in each chamber were recorded.

\section{Morris Water Maze Test}

The Morris water maze (MWM) was used to analyze reference spatial memory and was performed in a circular pool (diameter $120 \mathrm{~cm}$ ) filled with water at $22^{\circ} \mathrm{C}$, using a modified protocol (Zhao et al., 2018). Around the pool, recognizable and contrasting shapes were provided as reference cues, and a transparent platform (diameter $10 \mathrm{~cm}$ ) was submerged $1-2 \mathrm{~cm}$ under the water. In each trial, a mouse was placed into the water facing the wall of the pool at one of four points $(\mathrm{N}, \mathrm{S}, \mathrm{E}$, and $\mathrm{W})$ of the maze, selected at random. The mouse was allowed to find the platform for escape; if it had not found the platform after $60 \mathrm{~s}$, it was guided to the hidden platform. During the 4 days training, two trials were conducted daily separated by a $1 \mathrm{~h}$ interval, and the latency to reach the hidden platform (escape latency) was scored. In the probe test on day 5, the hidden platform was removed, and the time spent in each quadrant and the number of crossings over the original platform area were analyzed.

\section{Fear Conditioning Test}

A fear conditioning test was performed as previously described (Lee et al., 2017). This test was performed in a soundproof box $(22 \times 22 \times 30 \mathrm{~cm})$ with a metal grid floor capable of delivering an electric shock and a dim light installed in the ceiling. On the first day, the training day, each mouse was allowed to explore the chamber for $120 \mathrm{~s}$ to determine the basal freezing response. Then, the mouse was exposed to a tone $(80 \mathrm{~dB})$ for $30 \mathrm{~s}$ as a conditioning stimulus (CS) and a foot shock $(0.5 \mathrm{~mA})$ in the last $2 \mathrm{~s}$ as an unconditioned stimulus (US). Three CS-US trials were performed at $30 \mathrm{~s}$ intervals, and then the mouse was left undisturbed for another $1 \mathrm{~min}$. In the contextual test, each mouse was placed into the box without any stimulus $24 \mathrm{~h}$ after the training period, and freezing behavior was recorded for $5 \mathrm{~min}$. A cued test was also performed, in which each mouse was placed in the box and allowed to explore freely for $3 \mathrm{~min}$, followed by another $3 \mathrm{~min}$ in the presence of the CS. Subsequent tests were performed on day 3 and 6 after training to examine memory extinction. Animal freezing responses were recorded and analyzed by using the software (Panlab, Harvard Apparatus, Holliston, MA, United States).

\section{Novel Object Recognition Test}

The novel object recognition test, a non-force driving and spontaneous memory test, was performed. Before training, each mouse was allowed to habituate to the test space $(40 \times 40 \times 40 \mathrm{~cm})$ for $10 \mathrm{~min}$. During the training phase, the mouse was placed in the space with two identical objects, one in each of two corners, and allotted $10 \mathrm{~min}$ for exploration. 1 day later, the mouse was tested using the same procedure except that one object had been replaced with a novel object; the mouse was allowed to explore for $10 \mathrm{~min}$. Exploration time was considered to have started when the front paws or nose touch the objects and was analyzed as the discrimination index (DI), $\mathrm{DI}=\mathrm{T}_{\text {novel }} /\left(\mathrm{T}_{\text {novel }}+\mathrm{T}_{\text {familiar }}\right)$.

\section{Object Location Memory Test}

During this test, each mouse was allowed to freely explore the two objects in the training stage for $10 \mathrm{~min} .2 \mathrm{~h}$ later, one object was moved to a new position in the area, and the mouse was allowed to explore for $10 \mathrm{~min}$. Exploration time was recorded as an indicator of spatial memory.

\section{Statistical Analysis}

Unpaired $t$ tests were performed using GraphPad Prism software (GraphPad Software, San Diego, CA, United States). All data represent means \pm SEM. Statistical significance was evaluated at $P<0.05$.

\section{RESULTS}

\section{Generation of Human-SNX27 Transgenic Mice}

We first found that endogenous SNX27 was highly expressed in mouse cortex, hippocampus and cerebellum (Supplementary Figure 1A), and was mainly expressed in neurons and astrocytes, but with a relatively low expression in microglia (Supplementary Figure 1B). To further investigate the function of SNX27 in the central nervous system, we generated an SNX27 transgenic mouse model (hSNX27 $\mathrm{Tg}$ ) that overexpresses human SNX27 with a HA tag under the control of the mouse Camk2a promoter (Figure 1A). Successful generation of 


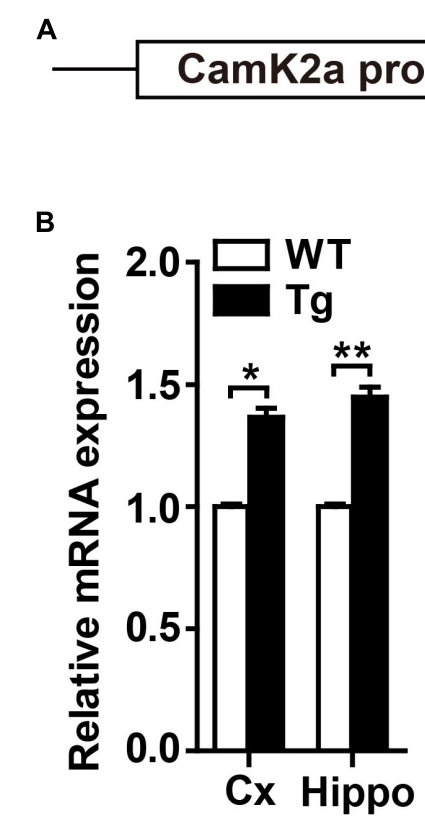

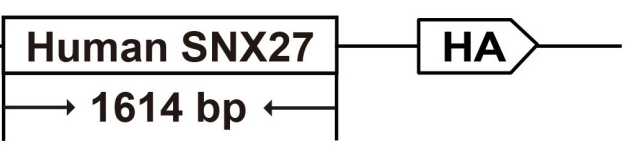

C
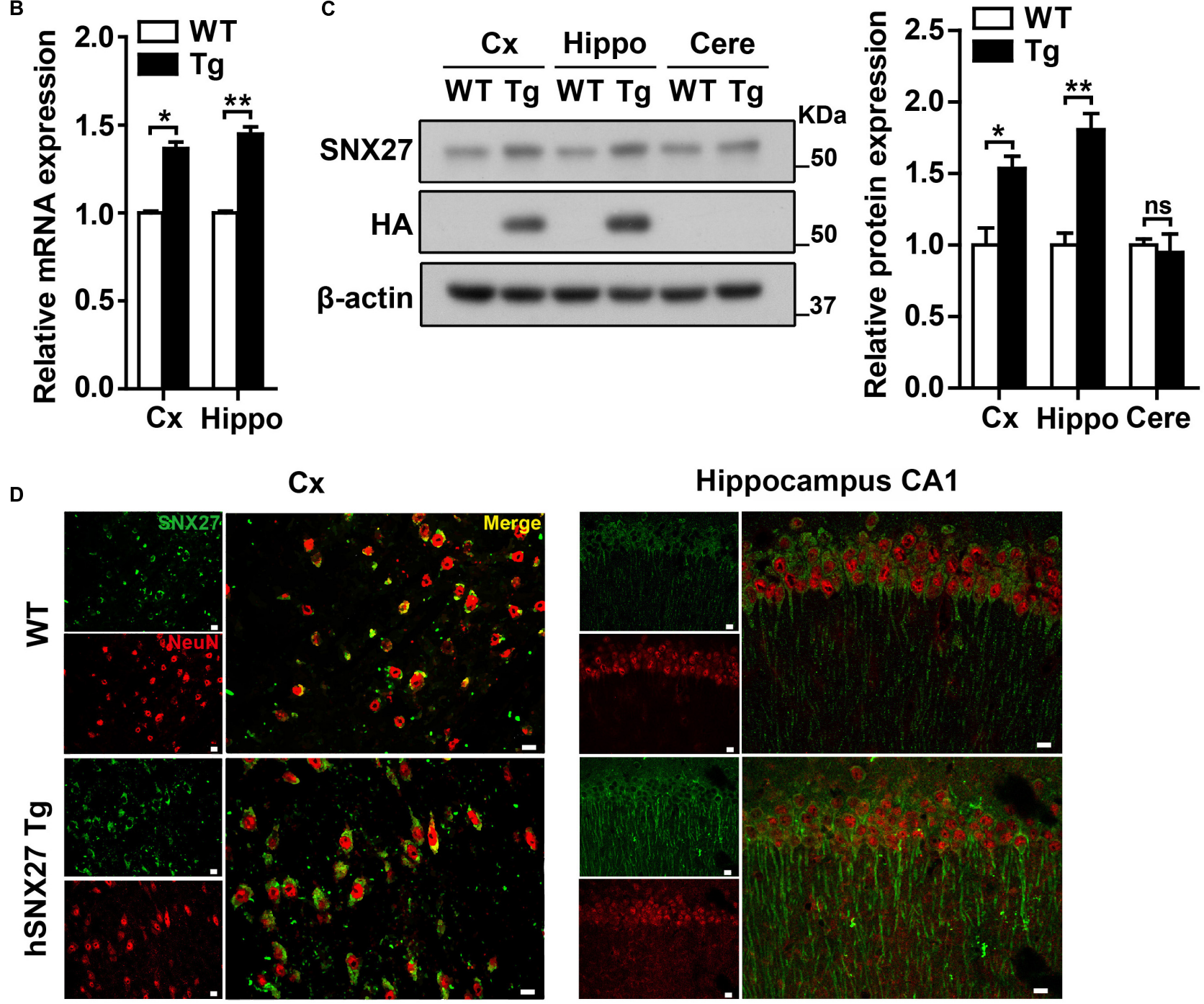

FIGURE 1 | Generation and characterization of human SNX27 (hSNX27) transgenic mice. (A) Schematic representation of the hSNX27 transgenic mouse. (B) SNX27 mRNA levels in WT and Tg mouse brains (Cx, cortex; Hippo, hippocampus) were determined by qRT-PCR; values were normalized to Actb. WT values were set as one arbitrary unit. Data represent mean \pm s.e.m. $(n=3)$. (C) Western blot analysis was conducted to determine SNX27 protein levels in cortex (Cx), hippocampus (Hippo), and cerebellum (Cere) of Tg mice. Lysates from WT were used as negative controls. (D) Brain slides from 2-month-old WT and Tg mice were immunostained with SNX27 (in green) and NeuN (in red) and observed by confocal microscopy. Scale bar $=10 \mu \mathrm{m}$. ns, not significant, ${ }^{\star} P<0.05,{ }^{\star \star} P<0.01$ (two-tailed unpaired $t$ test).

hSNX27 Tg mice was confirmed by PCR-based genotyping (Supplementary Figure 1C). Moreover, we examined the mRNA and protein levels of SNX27 in different brain regions of hSNX27 Tg mice and found higher SNX27 expression in cerebral cortex and hippocampus, but not cerebellum, in $\mathrm{h} S N X 27 \mathrm{Tg}$ mice than in WT littermates (Figures 1B,C). Furthermore, our immunohistochemical analysis indicated higher SNX27 expression in the cortical and hippocampal neurons of hSNX27 $\mathrm{Tg}$ mice compared to that in WT mice (Figure 1D and Supplementary Figures 1D,E).

\section{Overexpression of Human SNX27 Ameliorated Anxiety-Like Behavior and Sociability}

We carefully examined the hSNX27 Tg mice and found that $\mathrm{h} S N X 27 \mathrm{Tg}$ mice were grossly healthy, as the body weight gain 
and the ratio of genotypes were similar between hSNX27 Tg mice and their WT littermates (Supplementary Figures 2A,B). To determine whether SNX27 overexpression affects mouse behavior, we performed a series of behavioral tests using 2-3month-old mice. In the OFT, we found that hSNX27 Tg mice spent more time in the central region of the open field compared to WT mice; furthermore, hSNX27 Tg mice traveled a longer distance than WT mice did in the OFT (Figure 2A). In the EPM test, hSNX27 Tg mice displayed markedly longer openarm durations and more entry times compared to WT mice, and hSNX27 Tg mice traveled longer distances than WT controls (Figure 2B). However, hSNX27 Tg mice behaved similar to their WT littermates in the Light/Dark transition test (Supplementary Figure 3A). Interestingly, compared to WT mice, hSNX27 Tg
A

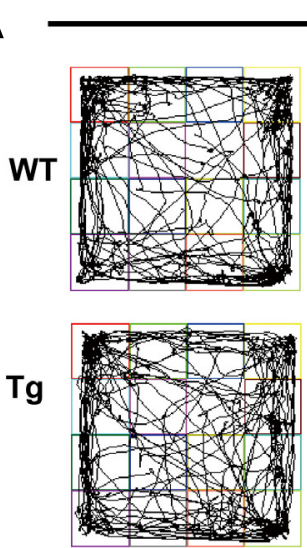

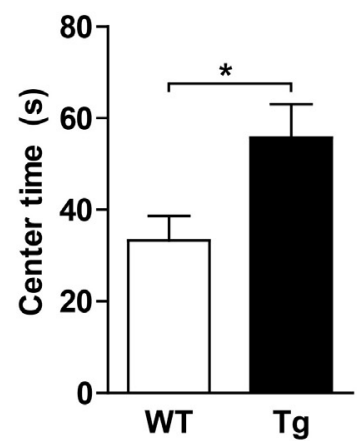
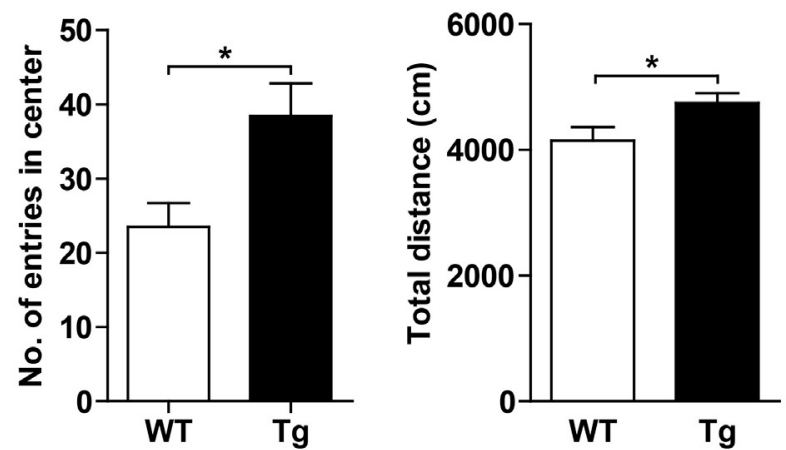

B Elevated plus maze

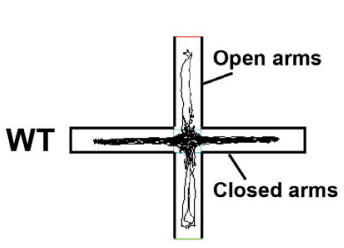

$\mathrm{Tg}$

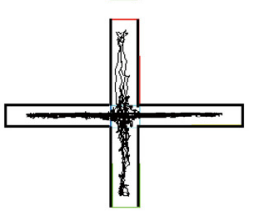

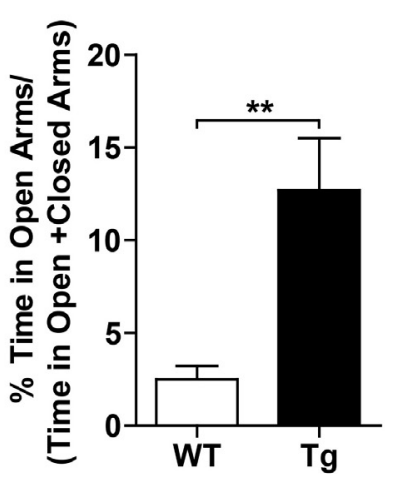
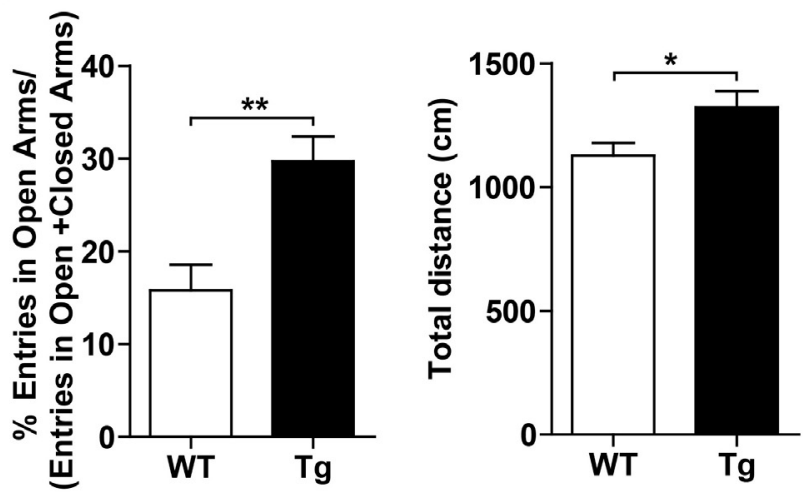

C

Social interaction test
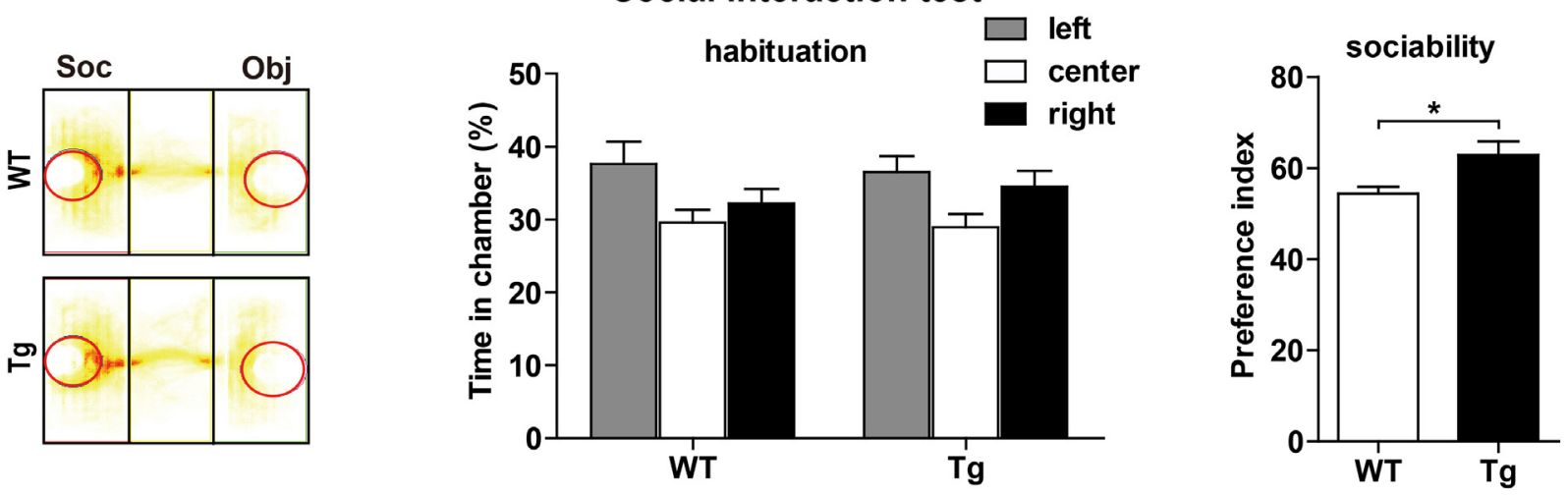

FIGURE 2 | Effects of SNX27 overexpression on anxiety-like behavior and social interaction. (A) Time spent in the center, number of entries into the center, and distance traveled in open field test were quantified and analyzed. (B) In the elevated plus maze test, WT and Tg mice were assessed for percentage of time spent in the open arms, percentage of entries into the open arms, and total distance they traveled. (C) The durations of social interaction were measured in a 10-min social interaction test. Representative traces are shown. Data represent mean \pm s.e.m. (WT, $n=14 ; \mathrm{Tg}, n=16) .{ }^{*} P<0.05,{ }^{* *} P<0.01$ (two-tailed unpaired $t$ test). 
A
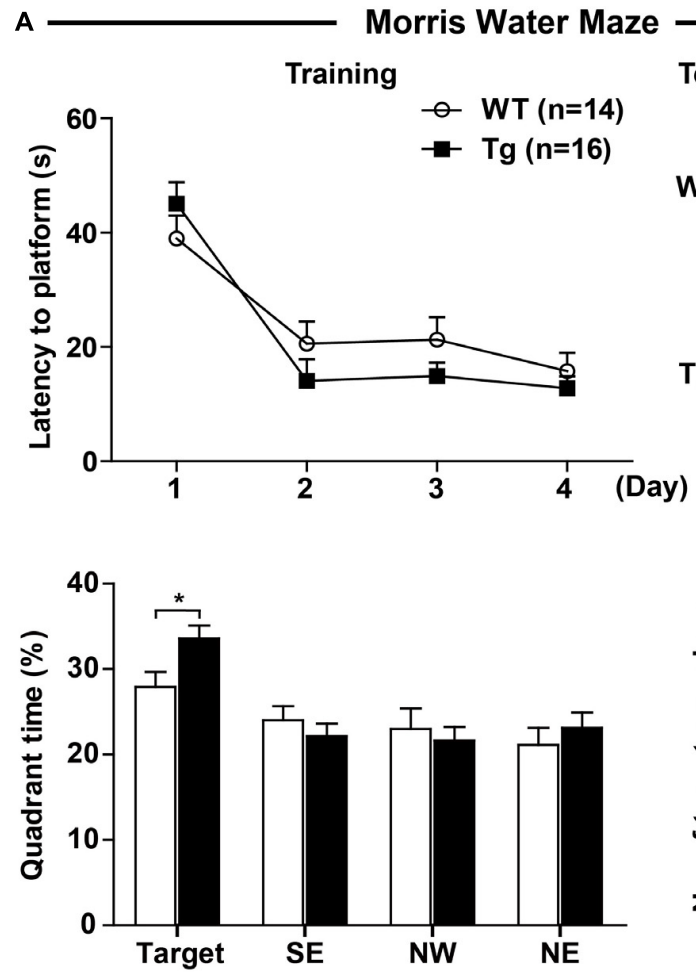

B Object Location Memory Test
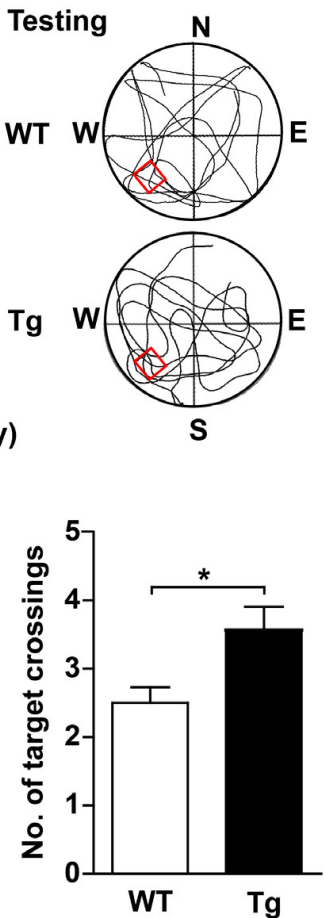

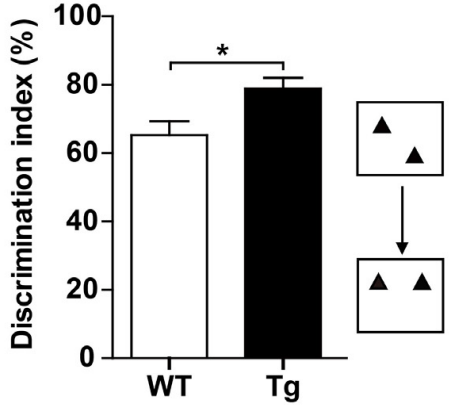

C Fear Conditioning

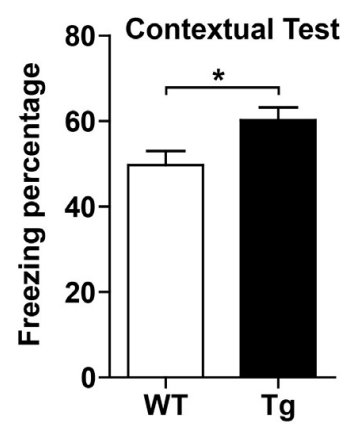

FIGURE 3 | SNX27 overexpression enhanced learning and memory in hSNX27 mice. (A) In the Morris water maze test, WT and Tg mice were evaluated for escape latency over a 4-day training. On the 5th day, percentage of time the mice spent in the target zone and the number of crossings over the platform region were quantified. (B) The object location memory test was conducted to assess the short-term (2 h) memory of WT and Tg mice. (C) In the fear conditioning test, freezing percentage was assessed to evaluate contextual memory $24 \mathrm{~h}$ after training. Representative traces are shown. Data represent mean $\pm \mathrm{s} . \mathrm{e} . \mathrm{m}$. (WT, $n=14$; and Tg, $n=16) .{ }^{*} P<0.05$ (two-tailed unpaired $t$ test).

mice displayed enhanced sociability in the three-chamber test (Figure 2C). Taken together, these results indicate that SNX27 overexpression increases social interaction and reduces anxietylike behavior in hSNX27 Tg mice.

\section{Overexpression of Human SNX27 Enhanced Spatial Memory}

Sorting nexin 27 is highly expressed in hippocampal neurons, suggesting a potential role in learning and memory ability, we therefore evaluated learning and memory of hSNX27 Tg mice. In the training phase of the MWM test, hSNX27 Tg mice behaved similar to WT mice (Figure 3A). However, in the probe test of MWM, hSNX27 Tg mice spent significantly more time in the target quadrant, underwent more platform crossings and required less time to reach the platform region than WT controls (Figure 3A and Supplementary Figure 3B), indicating that SNX27 overexpression enhances spatial memory in mice. However, there was no difference in total distance traveled between hSNX27 Tg and WT mice (Supplementary Figure 3B). In the novel object recognition test, hSNX27 Tg transgenic mice did not spend more time than WT mice in sniffing/exploring the novel object (Supplementary Figure 3C). However, we observed that hSNX27 Tg mice yielded a higher discrimination index than WT controls in the novel object location test (Figure 3B). In addition, hSNX27 Tg mice displayed significantly higher freezing percentages than WT mice in the fear conditioning contextual test (Figure 3C) but showed no difference from WT mice in the cued test (Supplementary Figure 3D). Together, these results indicate that SNX27 overexpression enhances learning and memory in mice.

\section{hSNX27 Mice Displayed Enhanced Synaptic Function}

To determine whether SNX27 overexpression affects synaptic function, we performed electrophysiological recordings using acute hippocampal slices from WT and hSNX27 mice. In input-output response, a significant increase in the amplitude of the evoked excitatory postsynaptic current (eEPSC) was detected in hSNX27 Tg mice relative to WT mice (Figure 4A). In addition, paired-pulse facilitation remains unchanged in hSNX27 Tg mice compared to WT mice (Figure 4B). Consistent with input-output response, enhanced LTP at hippocampal CA1 region was observed in $\mathrm{hSNX} 27$ mice compared to WT mice (Figure 4C), suggesting that SNX27 overexpression increases activity-dependent synaptic plasticity in hippocampus. Furthermore, hSNX27 Tg mice showed enhanced mEPSC amplitude but unaffected mEPSC frequency compared to WT mice (Figure 5A), suggesting that SNX27 overexpression 
A

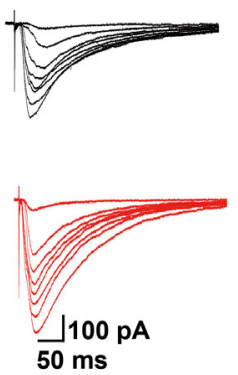

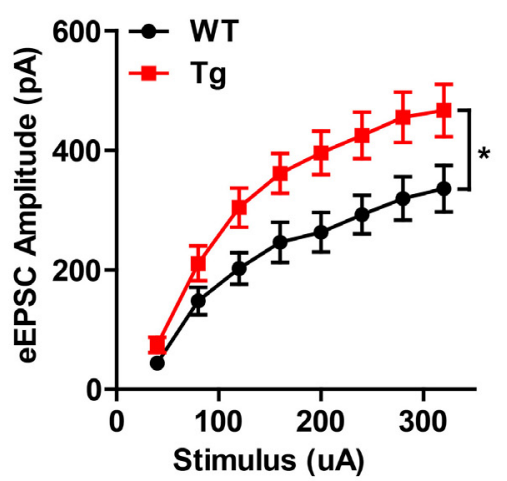

B
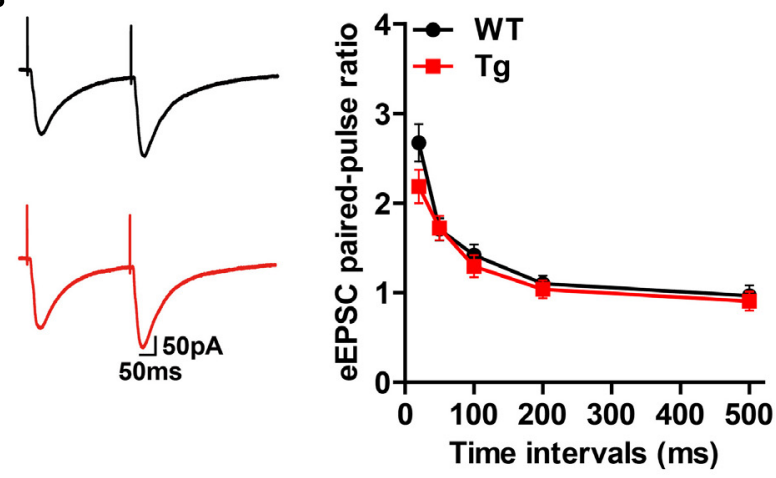

C
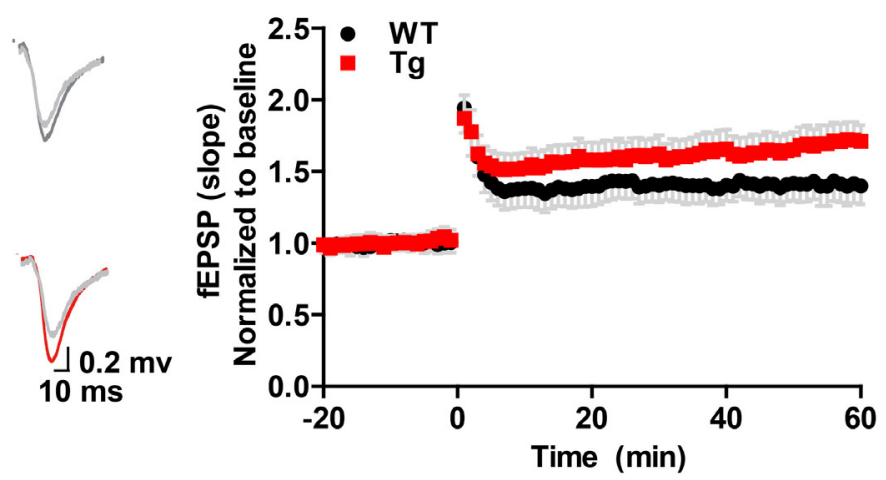

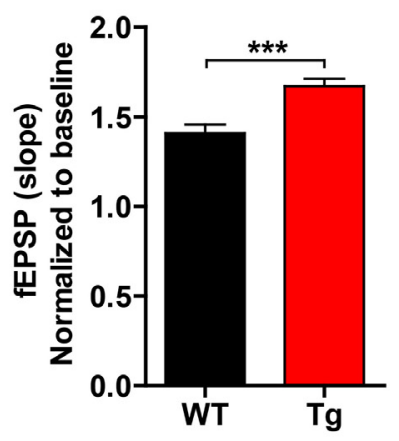

FIGURE 4 | Overexpression of human SNX27 promoted synaptic plasticity in hSNX27 mice. (A) Input-output response generated by stimulating the Schaffer-collateral pathway and recording in CA1 pyramidal neurons. (A, left) Representative traces of eEPSCs and quantitative analysis of eEPSC amplitude against stimulus intensity (A, right). eEPSCs were recorded at a holding potential of $-70 \mathrm{mV} . n=6-8$ cells per group. (B) Paired-pulse ratio analysis. (B, left) Representative traces of paired eEPSCs. (B, right) Summary of paired-pulse ratio against different time intervals. $n=6-8$ cells per group. (A,B) Data represent mean \pm s.e.m. ${ }^{*} P<0.05$ (repeated measures two-way ANOVA). (C) LTP was induced in the CA3-CA1 synapses. (C, left) Representative traces of fEPSP responses before and after high frequency stimulation (HFS). (C, middle) Time course of LTP are shown for WT and Tg mice; LTP was induced by two trains of 100-Hz stimuli in the Schaffer-collateral pathway. (C, right) Quantitative analysis of fEPSP potentiation was determined at a mean of 50-60 min after high frequency stimulation. $n=5-7$ slices per group. Data represent mean \pm s.e.m. ${ }^{*} P<0.05,{ }^{* \star *} P<0.001$ (two-tailed unpaired $t$ test).

A
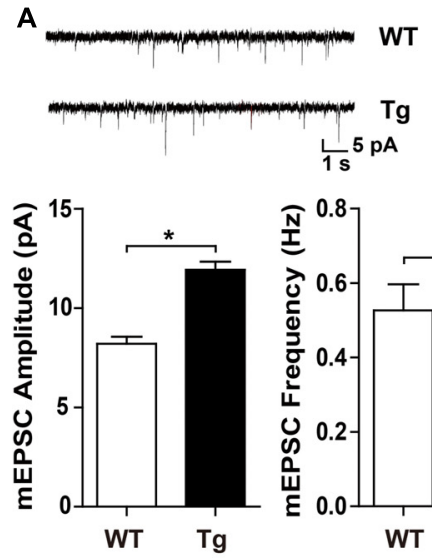

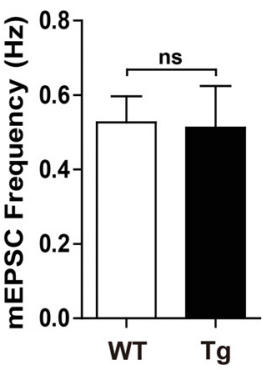

B

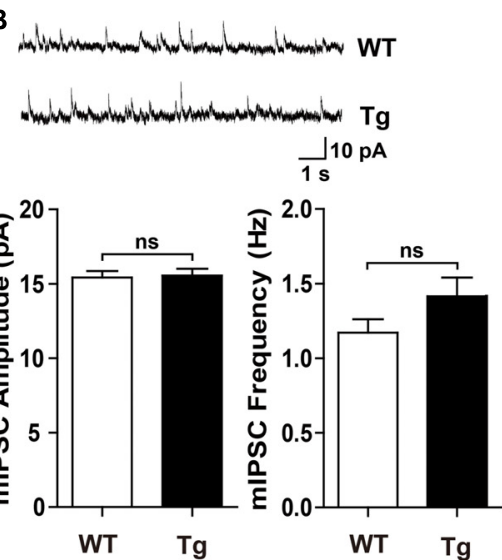

FIGURE 5 | hSNX27 transgenic mice displayed enhanced excitatory synaptic function. (A) (A, top) Representative traces of mEPSCs. mEPSCs were recorded at a holding potential of $-70 \mathrm{mV}$. Scale bar $=1 \mathrm{~s}, 5 \mathrm{pA}$. (A, bottom) Quantitative analysis of the amplitude (left) and frequency (right) of mEPSCs. $n=15 \mathrm{cells}$ per group. Data represent mean \pm s.e.m. (B) (B, top) Representative traces of mIPSCs. mIPSCs were recorded at a holding potential of $0 \mathrm{mV}$. Scale bar $=1 \mathrm{~s}, 10 \mathrm{pA}$. (B, bottom) Quantitative analysis of the amplitude (left) and frequency (right) of mIPSCs. $n=20$ cells per group. Data represent mean \pm s.e.m. ns, not significant, ${ }^{*} P<0.05$ (two-tailed unpaired $t$ test). 
enhances the amount and/or the function of postsynaptic AMPA and NMDA receptors. However, both amplitude and frequency of mIPSC were similar between hSNX27 Tg mice and WT littermates (Figure 5B). Moreover, excitation/inhibition balance (E/I ratio) was not affected by SNX27 overexpression in hSNX27 transgenic mice (Supplementary Figure 4). Together, these results demonstrate that SNX27 overexpression enhances excitatory synaptic transmission and synaptic plasticity in hSNX27 Tg mice.

\section{Overexpression of Human SNX27 Affected Synapse Formation}

Enhanced synaptic function is usually accompanied by dynamic alterations in synaptic density or structure, such as the formation of new synapses or the consolidation of existing synapses (Batool et al., 2019). We first performed Nissl staining and found that SNX27 overexpression did not affect the gross morphology of cortex and hippocampus of hSNX27 Tg mice (Figure 6A). To determine whether SNX27 overexpression affects synapse formation, we consequently performed Golgi staining and found an increased density of mature synapses and a decreased number of immature synapses in hippocampal neurons of 2-month-old hSNX27 Tg mice compared with that in WT littermates (Figure 6B), suggesting that SNX27 plays a key role in regulating synaptic structure and function without affecting gross brain morphology.

\section{Overexpression of Human SNX27 Upregulated the Expression of Synaptic Proteins}

To explore the underlying mechanism of enhanced synaptic function in hSNX27 Tg mice, we analyzed the expression of synaptic proteins, including glutamate receptors and postsynaptic scaffold proteins, and found an upregulated expression of glutamate receptors and the scaffold protein PSD95 in both cortex and hippocampus of hSNX27 Tg mice compared with WT controls (Figures 7A,B). However, the mRNA levels of glutamate receptors did not differ between the two groups (Supplementary Figure 5), suggesting that SNX27 overexpression modulates the expression of these receptors at the post-transcriptional level. In addition, SNX27 overexpression failed to affect the expression levels of inhibitory synaptic proteins, such as $\mathrm{GABA}_{A} \mathrm{R} \beta 3$ and GAD-65 (Supplementary Figure 6). Taken together, these results indicate that SNX27 overexpression increases excitatory synaptic function by upregulating the expression of glutamate receptors and PSD-associated proteins in mice.

\section{hSNX27 Transgenic Mice Did Not Display Seizure-Like Electroencephalogram (EEG)}

Given that hyperactivation of glutamate receptors may lead to excessive firing of neurons, we examined whether SNX27
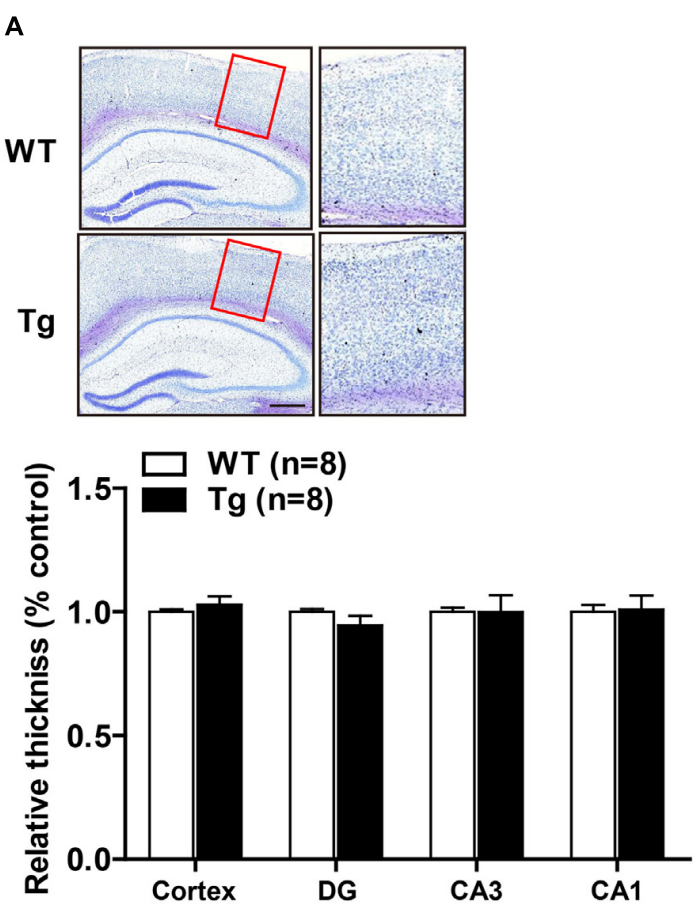

B
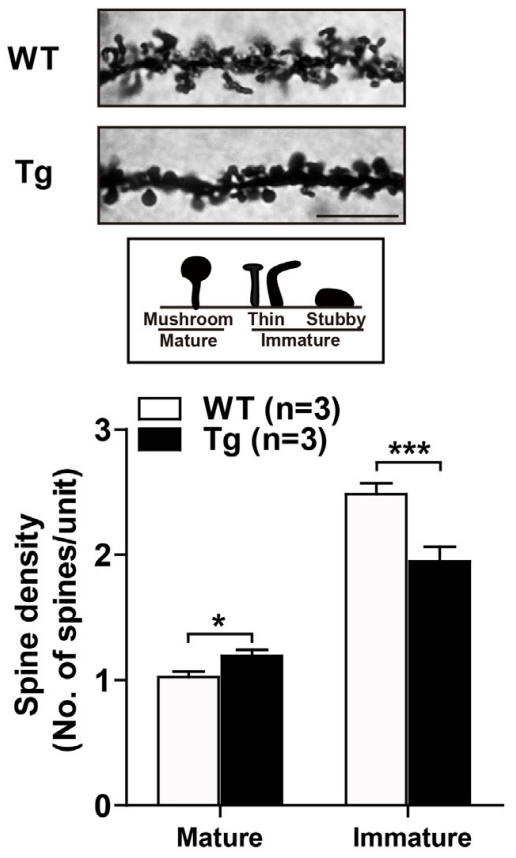

FIGURE 6 | Effects of SNX27 overexpression on synaptogenesis. (A) (A, top) Representative images of Nissl staining of WT and Tg brain slices. The zoom in regions were marked by a red box. Scale bar $=400 \mu \mathrm{m}$. (A, bottom) Cortical thickness. $n=8$. (B) (B, top) Representative images and illustrations of Golgi staining of hippocampal neurons of 2-month-old WT and Tg mice. Scale bar $=10 \mu \mathrm{m}$. (B, bottom) Spine densities of mature (mushroom) and immature (stubby and thin) neurons were quantified. Data represent mean \pm s.e.m. $\left(n=21-30\right.$ neurons from three mice per group). ${ }^{\star} P<0.05,{ }^{\star \star \star} P<0.001$ (two-tailed unpaired $t$ test). 

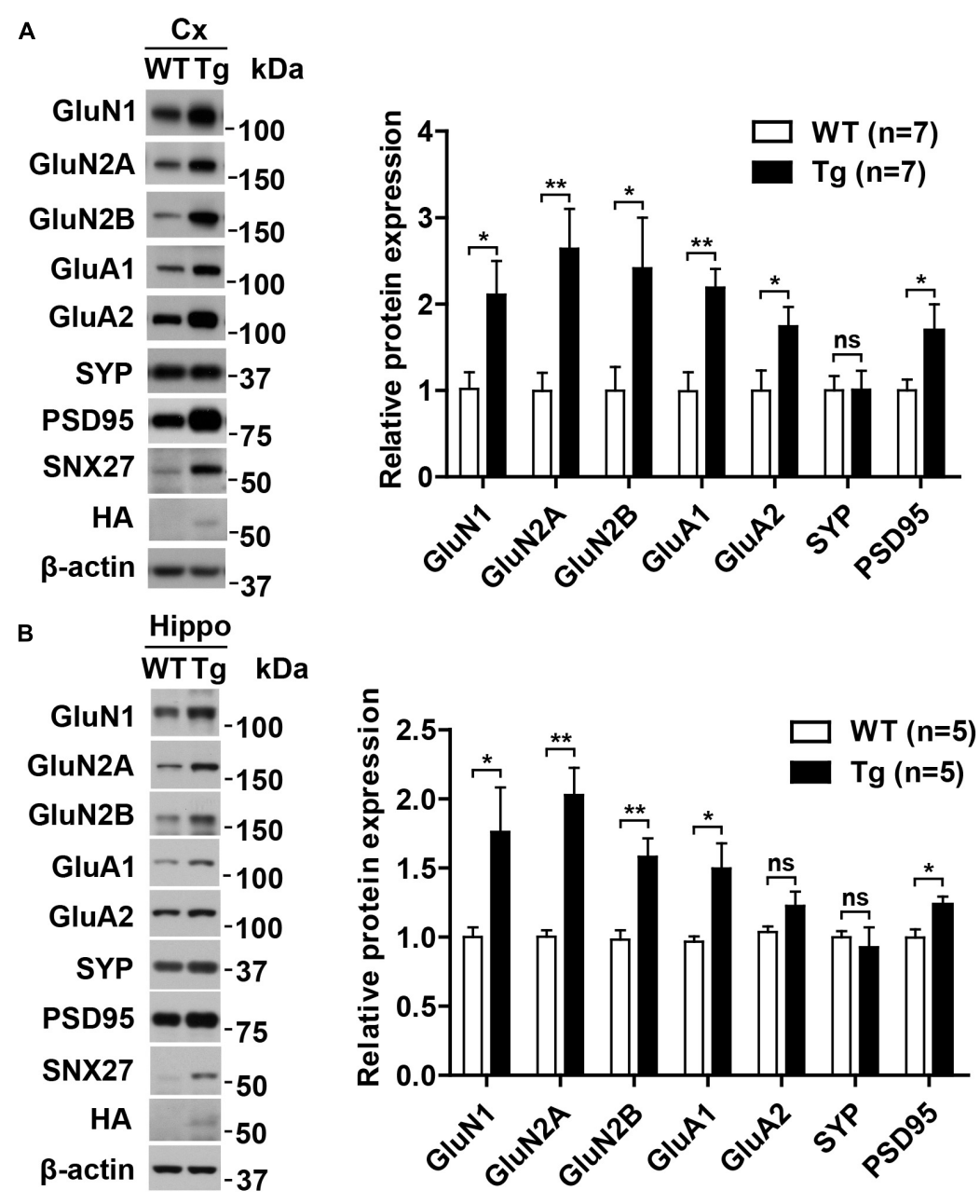

FIGURE 7 | Upregulation of NMDA and AMPA receptors in hSNX27 transgenic mice. (A,B) Total lysates from the cortex (A) and hippocampus (B) of 2-month-old $\mathrm{WT}$ and Tg mice were analyzed by western blot analysis. Protein levels were normalized to $\beta$-actin compared with WT. Data represent mean \pm s.e.m. $(n=3$ per group). ns, not significant, ${ }^{\star} P<0.05,{ }^{\star \star} P<0.01$ (two-tailed unpaired $t$ test).

overexpression results in epilepsy-like EEG (Figure 8A). In contrast to an induced seizure model (KA-injected mice), neither hSNX27 Tg nor WT mice displayed seizure-like episodes and EEG abnormalities (Figures 8B,C). Together, these results suggest that SNX27 overexpression does not induce seizurelike behavior.

\section{DISCUSSION}

Impaired synaptic function contributes to various neurological diseases, including autism spectrum disorders (ASD), DS, epilepsy and AD (Terry et al., 1991; Kril et al., 2002; Fernandez and Garner, 2007; Baudouin et al., 2012; Keezer et al., 2016; DeTure and Dickson, 2019; Guo et al., 2020). In our previous work, we found that SNX27 haploinsufficiency disrupts glutamate receptor recycling, leading to synaptic and cognitive deficits (Wang et al., 2013). In the current study, we further determined that overexpression of SNX27 enhances synaptic and cognitive function in $h S N X 27 \mathrm{Tg}$ mice. These findings demonstrate that SNX27 plays a key role in synaptic plasticity and cognitive function through regulating intracellular trafficking of inotropic glutamate receptors.

Previous studies have shown that the SNX27-retromer-WASH complex is involved in endosomal sorting and trafficking of protein cargoes. SNX27 serves as an adaptor protein to link multiple cargo proteins with the endosomal tubules through direct interactions. In addition, SNX27 interacts with VPS26 (a subunit of the retromer complex) through its PDZ domain to prevent lysosomal delivery and degradation of its cargoes (Seaman, 2004; Steinberg et al., 2013; Lee et al., 2016). In addition to glutamate receptors, future work will illustrate whether other cargo proteins of SNX27 are involved in the regulation of synaptic and cognitive function.

Synaptic function can be also regulated by the extracellular matrix and glial cells, which are referred to as the "tetrapartite synapse" (Chelini et al., 2018). In addition to neurons, SNX27 also plays important roles in normal function of glial cells. SNX27 
A

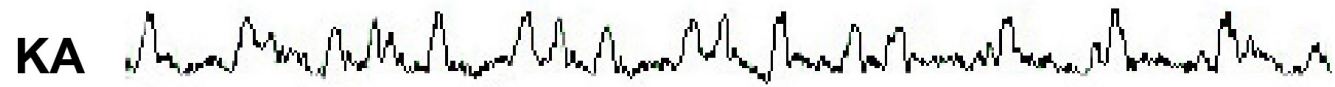

WT

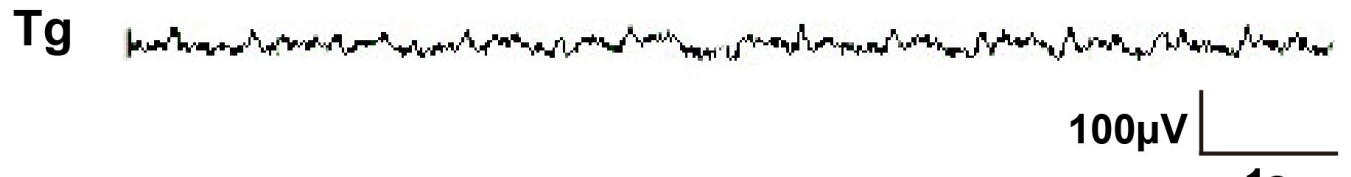

$1 \mathrm{~s}$

B

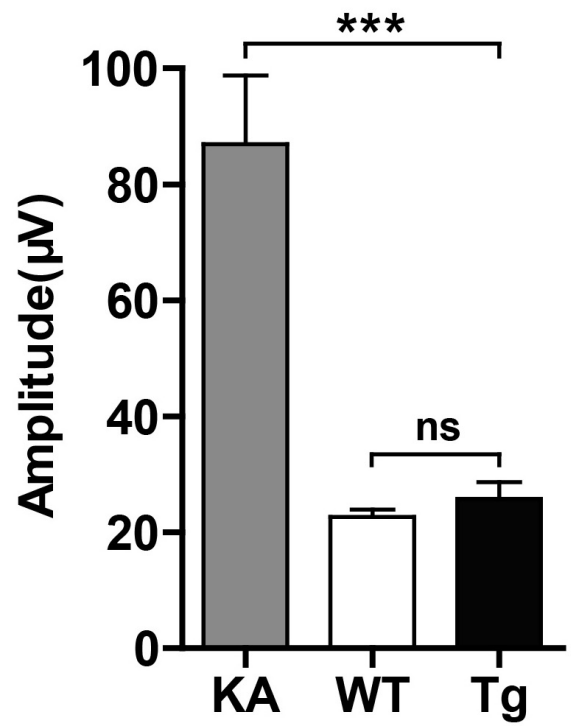

C

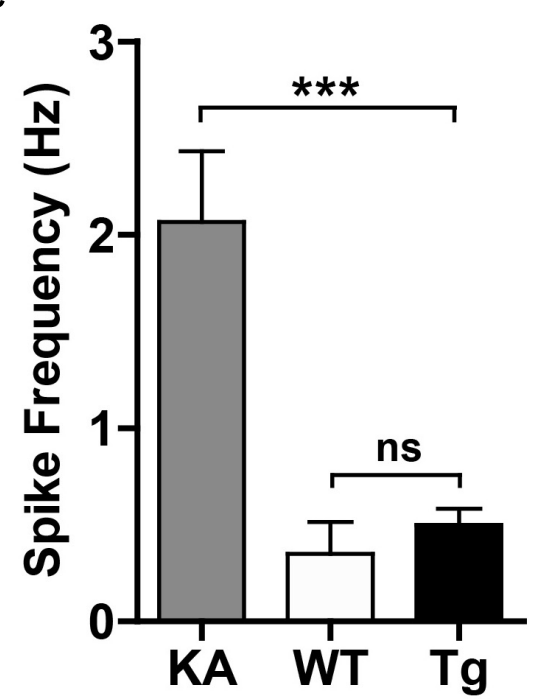

FIGURE 8 | SNX27 overexpression did not result in seizure-like EEG. (A) Representative EEG images. 2-month-old WT and Tg mice were recorded for EEG for $1 \mathrm{~h}$. C57BL/6 mice were injected with KA as positive control and subjected to EEG recording for $2 \mathrm{~h}$ after injection. (B,C) The amplitude (B) and spike frequency (C) of EEG were quantified for comparison. $n=3$ mice. Data represent mean \pm s.e.m. ( $n=3$ per group). ns, not significant, ${ }^{\star \star \star} P<0.001$ (one-way ANOVA with Turkey post hoc analysis).

is expressed in oligodendrocytes and mediates the intracellular delivery of GPR17 to the plasma membrane, and participates in the development of oligodendrocytes and myelin sheath (Meraviglia et al., 2016). In our study, we also confirmed the expression of SNX27 in astrocytes. Given that astrocytes act as the supporting cells which provides lactate/pyruvate to neurons, and the roles of astrocytes in regulating synapse maturation and synaptic plasticity (Bosworth and Allen, 2017; BlancoSuarez et al., 2018; Hillen et al., 2018; Scofield, 2018), SNX27 may regulates synaptic plasticity through modulating astrocytic function, and the cell-type-specific functions of SNX27 require careful investigation in the future studies.

Human-SNX27 Tg mice exhibited altered social and anxietylike behavior. It has been reported that abnormal NMDAR activity contributes to impaired social interaction and anxietylike behavior in mice (Planaguma et al., 2015; Zhang et al., 2016; Peyrovian et al., 2019). In the future study, the mechanisms by which SNX27 influences anxiety-like behavior need further investigation.
In summary, our results indicate that SNX27 promotes glutamate receptor recycling and enhances synaptic and cognitive function without inducing seizure-like behavior and EEG in hSNX27 transgenic mice. Our results suggest SNX27 as a potential therapeutic target for treating intellectual disability and other neurodegenerative diseases.

\section{DATA AVAILABILITY STATEMENT}

The original contributions presented in the study are included in the article/Supplementary Material, further inquiries can be directed to the corresponding author.

\section{ETHICS STATEMENT}

The animal study was reviewed and approved by the Institutional Animal Care and Use Committee of Xiamen University. 


\section{AUTHOR CONTRIBUTIONS}

$\mathrm{XW}$ conceptualized the study and designed the experiments. $\mathrm{YH}$ performed the behavioral tests and biochemical assays. DZ, TG, SZ, and YZe performed the morphological analysis. YG and YC performed the electrophysiological recording. QZ, HG, LZ, and BZ performed the molecular biology experiments. Y-wZ and HS supervised DZ and YG, respectively. $\mathrm{YH}$ and $\mathrm{XW}$ wrote the manuscript. DZ, HL, XZ, YZh and HX discussed and edited the manuscript. XW supervised the project. All authors contributed to the article and approved the submitted version.

\section{FUNDING}

This work was supported in part by the National Natural Science Foundation of China (31871077, 81822014, and 81571176 to XW; 81471160 to HS; 81701130 to QZ; 81802823 to YZh), the National

\section{REFERENCES}

Acquarone, E., Argyrousi, E. K., Van Den Berg, M., Gulisano, W., Fà, M., Staniszewski, A., et al. (2019). Synaptic and memory dysfunction induced by tau oligomers is rescued by up-regulation of the nitric oxide cascade. Mol. Neurodegener. 14:26.

Batool, S., Raza, H., Zaidi, J., Riaz, S., Hasan, S., and Syed, N. I. (2019). Synapse formation: from cellular and molecular mechanisms to neurodevelopmental and neurodegenerative disorders. J. Neurophysiol. 121, 1381-1397. doi: 10. 1152/jn.00833.2018

Baudouin, S. J., Gaudias, J., Gerharz, S., Hatstatt, L., Zhou, K., Punnakkal, P., et al. (2012). Shared synaptic pathophysiology in syndromic and nonsyndromic rodent models of autism. Science 338, 128-132. doi: 10.1126/science.1224159

Blanco-Suarez, E., Liu, T. F., Kopelevich, A., and Allen, N. J. (2018). Astrocytesecreted chordin-like 1 drives synapse maturation and limits plasticity by increasing synaptic GluA2 AMPA receptors. Neuron 100, 1116.e3-1132.e3.

Bosworth, A. P., and Allen, N. J. (2017). The diverse actions of astrocytes during synaptic development. Curr. Opin. Neurobiol. 47, 38-43. doi: 10.1016/j.conb. 2017.08.017

Buckmaster, P. S., and Lew, F. H. (2011). Rapamycin suppresses mossy fiber sprouting but not seizure frequency in a mouse model of temporal lobe epilepsy. J. Neurosci. 31, 2337-2347. doi: 10.1523/jneurosci.4852-10.2011

Cai, L., Loo, L. S., Atlashkin, V., Hanson, B. J., and Hong, W. (2011). Deficiency of sorting nexin 27 (SNX27) leads to growth retardation and elevated levels of N-methyl-D-aspartate receptor 2C (NR2C). Mol. Cell. Biol. 31, 1734-1747. doi: $10.1128 / \mathrm{mcb} .01044-10$

Chakroborty, S., Hill, E. S., Christian, D. T., Helfrich, R., Riley, S., Schneider, C., et al. (2019). Reduced presynaptic vesicle stores mediate cellular and network plasticity defects in an early-stage mouse model of Alzheimer's disease. Mol. Neurodegener. 14:7.

Chelini, G., Pantazopoulos, H., Durning, P., and Berretta, S. (2018). The tetrapartite synapse: a key concept in the pathophysiology of schizophrenia. Eur. Psychiatry 50, 60-69. doi: 10.1016/j.eurpsy.2018.02.003

Chen, W., Shieh, C., Swanger, S. A., Tankovic, A., Au, M., Mcguire, M., et al. (2017). GRIN1 mutation associated with intellectual disability alters NMDA receptor trafficking and function. J. Hum. Genet. 62, 589-597. doi: 10.1038/jhg.2017.19

Cullen, P. J. (2008). Endosomal sorting and signalling: an emerging role for sorting nexins. Nat. Rev. Mol. Cell. Biol. 9, 574-582. doi: 10.1038/nrm2427

Damseh, N., Danson, C. M., Al-Ashhab, M., Abu-Libdeh, B., Gallon, M., Sharma, K., et al. (2015). A defect in the retromer accessory protein, SNX27, manifests by infantile myoclonic epilepsy and neurodegeneration. Neurogenetics 16, $215-$ 221. doi: 10.1007/s10048-015-0446-0

DeTure, M. A., and Dickson, D. W. (2019). The neuropathological diagnosis of Alzheimer's disease. Mol. Neurodegener. 14:32.
Key R\&D Program of China (2016YFC1305900 to XW and HS), the Natural Science Foundation of Fujian Province of China (2017J06021 to XW), and the Fundamental Research Funds for the Chinese Central Universities (20720150061 to XW).

\section{ACKNOWLEDGMENTS}

We thank all members of the laboratory for their kindness and help and Xiamen University Laboratory Animal Center for animal care.

\section{SUPPLEMENTARY MATERIAL}

The Supplementary Material for this article can be found online at: https://www.frontiersin.org/articles/10.3389/fcell.2020. 595357/full\#supplementary-material

Fernandez, F., and Garner, C. C. (2007). Over-inhibition: a model for developmental intellectual disability. Trends Neurosci. 30, 497-503. doi: 10. 1016/j.tins.2007.07.005

Gallon, M., Clairfeuille, T., Steinberg, F., Mas, C., Ghai, R., Sessions, R. B., et al. (2014). A unique PDZ domain and arrestin-like fold interaction reveals mechanistic details of endocytic recycling by SNX27-retromer. Proc. Natl. Acad. Sci. U.S.A. 111, E3604-E3613.

Geisheker, M. R., Heymann, G., Wang, T., Coe, B. P., Turner, T. N., Stessman, H. A. F., et al. (2017). Hotspots of missense mutation identify neurodevelopmental disorder genes and functional domains. Nat. Neurosci. 20, 1043-1051. doi: 10.1038/nn.4589

Guo, T. T., Zhang, D. H., Zeng, Y. Z., Huang, T. Y., Xu, H. X., and Zhao, Y. J. (2020). Molecular and cellular mechanisms underlying the pathogenesis of Alzheimer's disease. Mol. Neurodegen. 15:40.

Hillen, A. E. J., Burbach, J. P. H., and Hol, E. M. (2018). Cell adhesion and matricellular support by astrocytes of the tripartite synapse. Prog. Neurobiol. 165-167, 66-86. doi: 10.1016/j.pneurobio.2018.02.002

Hu, C., Chen, W., Myers, S. J., Yuan, H., and Traynelis, S. F. (2016). Human GRIN2B variants in neurodevelopmental disorders. J. Pharmacol. Sci. 132, 115-121. doi: 10.1016/j.jphs.2016.10.002

Kasai, H., Fukuda, M., Watanabe, S., Hayashi-Takagi, A., and Noguchi, J. (2010). Structural dynamics of dendritic spines in memory and cognition. Trends Neurosci. 33, 121-129. doi: 10.1016/j.tins.2010.01.001

Keezer, M. R., Sisodiya, S. M., and Sander, J. W. (2016). Comorbidities of epilepsy: current concepts and future perspectives. Lancet Neurol. 15, 106-115. doi: 10.1016/s1474-4422(15)00225-2

Kessels, H. W., and Malinow, R. (2009). Synaptic AMPA receptor plasticity and behavior. Neuron 61, 340-350. doi: 10.1016/j.neuron.2009.01.015

Kril, J. J., Patel, S., Harding, A. J., and Halliday, G. M. (2002). Neuron loss from the hippocampus of Alzheimer's disease exceeds extracellular neurofibrillary tangle formation. Acta Neuropathol. 103, 370-376. doi: 10.1007/s00401-001-0477-5

Lee, K. I., Lin, H. C., Lee, H. T., Tsai, F. C., and Lee, T. S. (2017). Loss of transient receptor potential ankyrin 1 channel deregulates emotion, learning and memory, cognition, and social behavior in mice. Mol. Neurobiol. 54, 3606-3617. doi: 10.1007/s12035-016-9908-0

Lee, S., Chang, J., and Blackstone, C. (2016). FAM21 directs SNX27-retromer cargoes to the plasma membrane by preventing transport to the Golgi apparatus. Nat. Commun. 7:10939.

Malenka, R. C. (2003). The long-term potential of LTP. Nat. Rev. Neurosci. 4, 923-926. doi: 10.1038/nrn1258

Meraviglia, V., Ulivi, A. F., Boccazzi, M., Valenza, F., Fratangeli, A., Passafaro, M., et al. (2016). SNX27, a protein involved in down syndrome, regulates GPR17 trafficking and oligodendrocyte differentiation. Glia 64, 1437-1460. doi: $10.1002 /$ glia.23015 
Niciu, M. J., Kelmendi, B., and Sanacora, G. (2012). Overview of glutamatergic neurotransmission in the nervous system. Pharmacol. Biochem. Behav. 100, 656-664. doi: 10.1016/j.pbb.2011.08.008

Peyrovian, B., Rosenblat, J. D., Pan, Z., Iacobucci, M., Brietzke, E., and Mcintyre, R. S. (2019). The glycine site of NMDA receptors: a target for cognitive enhancement in psychiatric disorders. Prog. Neuropsychopharmacol. Biol. Psychiatry 92, 387-404. doi: 10.1016/j.pnpbp.2019.02.001

Planaguma, J., Leypoldt, F., Mannara, F., Gutierrez-Cuesta, J., Martin-Garcia, E., Aguilar, E., et al. (2015). Human N-methyl D-aspartate receptor antibodies alter memory and behaviour in mice. Brain 138, 94-109. doi: 10.1093/brain/awu310

Schulz, J. B., and Hausmann, L. (2016). Synaptopathies: synaptic dysfunction in neurological disorders - A review written by students for students, and a story of success for ISN schools. J. Neurochem. 138, 783-784. doi: 10.1111/jnc.13755

Scofield, M. D. (2018). Exploring the role of astroglial glutamate release and association with synapses in neuronal function and behavior. Biol. Psychiatry 84, 778-786. doi: 10.1016/j.biopsych.2017.10.029

Seaman, M. N. (2004). Cargo-selective endosomal sorting for retrieval to the Golgi requires retromer. J. Cell. Biol. 165, 111-122. doi: 10.1083/jcb.200312034

Seet, L. F., and Hong, W. (2006). The Phox (PX) domain proteins and membrane traffic. Biochim. Biophys. Acta 1761, 878-896. doi: 10.1016/j.bbalip.2006.04.011

Sheng, M., and Kim, E. (2011). The postsynaptic organization of synapses. Cold Spring Harb. Perspect. Biol. 3:a005678. doi: 10.1101/cshperspect.a005678

Steinberg, F., Gallon, M., Winfield, M., Thomas, E. C., Bell, A. J., Heesom, K. J., et al. (2013). A global analysis of SNX27-retromer assembly and cargo specificity reveals a function in glucose and metal ion transport. Nat. Cell. Biol. 15, 461-471. doi: 10.1038/ncb2721

Terry, R. D., Masliah, E., Salmon, D. P., Butters, N., Deteresa, R., Hill, R., et al. (1991). Physical basis of cognitive alterations in Alzheimer's disease: synapse loss is the major correlate of cognitive impairment. Ann. Neurol. 30, 572-580.

Van Acker, Z. P., Bretou, M., and Annaert, W. (2019). Endo-lysosomal dysregulations and late-onset Alzheimer's disease: impact of genetic risk factors. Mol. Neurodegener. 14:20.

Wang, X., Huang, T., Zhao, Y., Zheng, Q., Thompson, R. C., Bu, G., et al. (2014). Sorting nexin 27 regulates $A \beta$ production through modulating $\gamma$-secretase activity. Cell. Rep. 9, 1023-1033. doi: 10.1016/j.celrep.2014.09.037
Wang, X., Zhao, Y., Zhang, X., Badie, H., Zhou, Y., Mu, Y., et al. (2013). Loss of sorting nexin 27 contributes to excitatory synaptic dysfunction by modulating glutamate receptor recycling in Down's syndrome. Nat. Med. 19, 473-480. doi: $10.1038 / \mathrm{nm} .3117$

Worby, C. A., and Dixon, J. E. (2002). Sorting out the cellular functions of sorting nexins. Nat. Rev. Mol. Cell. Biol. 3, 919-931. doi: 10.1038/nrm974

Zeng, F., Ma, X., Zhu, L., Xu, Q., Zeng, Y., Gao, Y., et al. (2019). The deubiquitinase USP6 affects memory and synaptic plasticity through modulating NMDA receptor stability. PLoS Biol. 17:e3000525. doi: 10.1371/journal.pbio.3000525

Zhang, H., Kang, E., Wang, Y., Yang, C., Yu, H., Wang, Q., et al. (2016). Brainspecific Crmp2 deletion leads to neuronal development deficits and behavioural impairments in mice. Nat. Commun. 7:11773.

Zhao, D., Meng, J., Zhao, Y., Huo, Y., Liu, Y., Zheng, N., et al. (2018). RPS23RG1 is required for synaptic integrity and rescues Alzheimer's disease-associated cognitive deficits. Biol. Psychiatry 86, 171-184. doi: 10.1016/j.biopsych.2018. 08.009

Zheng, H., Tang, R., Yao, Y., Ji, Z., Cao, Y., Liu, Z., et al. (2016). MiR-219 protects against seizure in the kainic acid model of epilepsy. Mol. Neurobiol. 53, 1-7. doi: 10.1007/s12035-014-8981-5

Zheng, Q., Zheng, X., Zhang, L., Luo, H., Qian, L., Fu, X., et al. (2017). The neuron-specific protein TMEM59L mediates oxidative stress-induced cell death. Mol. Neurobiol. 54, 4189-4200. doi: 10.1007/s12035-0169997-9

Conflict of Interest: The authors declare that the research was conducted in the absence of any commercial or financial relationships that could be construed as a potential conflict of interest.

Copyright (c) $2020 \mathrm{Huo}$, Gao, Zheng, Zhao, Guo, Zhang, Zeng, Cheng, Gu, Zhang, Zhu, Luo, Zhang, Zhou, Zhang, Sun, Xu and Wang. This is an open-access article distributed under the terms of the Creative Commons Attribution License (CC BY). The use, distribution or reproduction in other forums is permitted, provided the original author(s) and the copyright owner(s) are credited and that the original publication in this journal is cited, in accordance with accepted academic practice. No use, distribution or reproduction is permitted which does not comply with these terms. 